\title{
UNDERGRADUATE WRITING ASSIGNMENTS IN ENGINEERING: TARGETING COMMUNICATION SKILLS (Attribute 7)
}

\author{
Anne Parker, Ph.D., and Kathryn Marcynuk, Vanier Scholar \\ Centre for Engineering Professional Practice and Engineering Education \\ University of Manitoba \\ Anne.Parker@umanitoba.ca; ummarcyk@,cc.umanitoba.ca
}

\begin{abstract}
This paper will report on some of our findings from a national study investigating the writing demands placed on students in various disciplines, including Engineering. This is a timely study given that Reave notes that a "well-designed program [in Engineering] will include a solid foundation in communication skills," something she says also requires high quality feedback. For our part of the study, we investigated which courses in our Engineering school target Attribute 7 (A7, Communication Skills) and then analyzed the course syllabi to determine whether they required written assignments. We then described these assignments according to 20 variables, such as the total number of assignments written per year, feedback provided and genre.
\end{abstract}

Ever since the accreditation board introduced them, the graduate attributes and their assessment have become the focus of most Engineering schools, so much so that Engineering course syllabi will necessarily include both a series of course outcomes and a complex chart of the expected competency levels. However, information on the assignments themselves can be far less detailed. Consequently, our findings tend to be more suggestive than definitive, though certain trends do stand out. For example, while many writing scholars, such as Paretti and Reave, would argue that students should learn the various discipline-specific writing genres and then be able to shape their material to satisfy the specific rhetorical demands, many course syllabi in our study simply listed "assignments" rather than specifying the kind of assignment: Civil Engineering listed 16 "assignments" of 33 (total) and Mechanical Engineering 47 of 105.

Finally, even though this paucity of detail may reflect what Broadhead calls the general "paucity of requirements for writing instruction" in an Engineering school, one of the goals of the national study was to initiate discussions about the way writing is taught and supported within the departments of the schools involved. Our study's findings, suggestive as they are, may be able to initiate that discussion.

Keywords: Writing assignments, Engineering undergraduate courses, Attribute 7, communication skills

\section{INTRODUCTION}

This paper reports on our findings from a national study that explores writing in the disciplines. To date, this national study, which originated at the University of Alberta under the direction of Roger Graves, has included 11 institutions and more than 36 departments, including departments in Engineering. Its goal is to provide systematic research about the various writing demands placed on undergraduate students in a variety of disciplines and then to map these demands so that a "program profile" [2] can be created. Ultimately, the findings are intended to help initiate discussions at the department and faculty levels on the way writing is taught and supported within a specific discipline, such as our focus, Engineering.

To that end, the national study looked at 20 variables, including "nesting" or linking of assignments, the audience for an assignment, the length of an assignment and the time allotted to complete it, grading criteria and feedback provided, the required genre, and the frequency of assignments according to program year. We define a "written assignment" as a self-contained unit of discourse where students are required to write extended prose in the documents they submit, so in-class and out-ofclass written assignments were all counted.

Our study in Engineering is a timely one, given that Laura Reave has argued that a "welldesigned program [in Engineering] includes a foundation in communication skills" as well as high "quality feedback" and high quality instruction [14]. The goal is to graduate engineers who are "communicatively competent," which we have defined as proficient in communicating the engineering work graphically, orally and in writing. 


\section{UNDERGRADUATE WRITTEN ASSIGNMENTS IN ENGINEERING}

In Engineering, we have defined Attribute 7, "Communication Skills," as the ability to communicate complex engineering concepts within the profession and with society at large [1]. Since C.E.A.B. first introduced these 12 attributes and outcome-based assessment, industry stakeholders have repeatedly emphasized the critical importance of communication skills (and teamwork skills) in the workplace [5], [10] and, as a result, these stakeholders have stressed the need for schools to integrate communication and engineering such that students can appreciate how the two are integrated in practice [10]. Yet, most schools, beyond introducing some variation of a technical writing course, have struggled to find effective ways to do that [10]. For one thing, although many schools have some courses that include some kind of written assignment, typically that will be a lab report, one that graduate teaching assistants will mark. Consequently, both the writing quality and the quality of the feedback may be minimal. So, unlike the other attributes, identifying and tracking the ubiquity of Attribute 7 in particular has often proven to be problematic.

This paper will report on our effort to track Attribute 7 by collecting the course syllabi from the departments of Mechanical Engineering, Electrical and Computer Engineering, and Civil Engineering. Each outline contains a brief description of the course, the mark breakdown and the learning outcomes mapped to both C.E.A.B. attributes as well as to competency levels, based on Bloom's taxonomy (where "knowledge" is the lowest level, "application" and "analysis" are the middle levels, and "evaluation" is the highest level). The main indicator for writing content was the inclusion of Attribute 7, "Communication Skills," on the course outline; as such, only courses that identified attribute 7 were assumed to have writing components.

Because each course syllabus must outline both the graduate attributes targeted by the course as well as the outcomes, we looked specifically for Attribute 7 in 133 courses; of these, 95 identified Attribute 7 . We then extracted data about the writing content of these courses by focusing on the 20 variables. In this paper, we will look at the total number of assignments (by year in the program) for each of these departments; the average number of written assignments per course; assignment genres; and the kind of feedback provided (formative or summative). For each course that identified Attribute 7, the types of assignments and their respective percent values were also recorded. Since undergraduate students take courses from multiple faculties to fulfill the requirements of their degree, only courses offered by the Faculty of Engineering were included in the study.

\section{THE FINDINGS}

There were a number of difficulties encountered as we began our data collection, not the least of which was trying to determine the writing content of each course that listed Attribute 7. The course outlines did not always describe the type of work required, nor did they explicitly list each assignment. Consequently, we had to make a number of assumptions. We assumed that all included courses are offered each year for students. For those courses that identified Attribute 7, the most common genres listed were "assignments," "lab reports" and "design projects." However, since the work required for these was not usually stated, we assumed that they contained writing components unless explicitly indicated otherwise. As well, tests and exams were not included as contributing to the writing content of a course.

Figure 1 below shows the number of course syllabi that identify Attribute 7 and link this attribute to a level of competency. In Electrical and Computer Engineering, 47 syllabi identified Attribute 7 and linked it to a level of ompetency, while Mechanical Engineering had 37 instances. The department with the fewest number of syllabi to identify Attribute 7 was Civil Engineering with just 14 courses included in the sample.

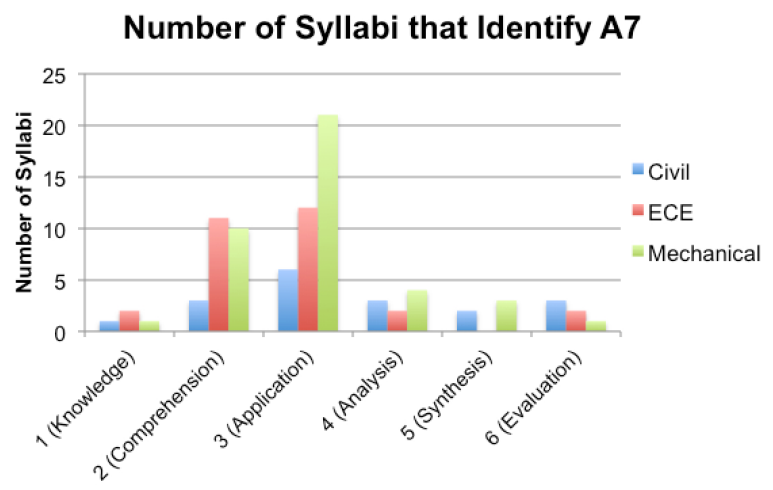

Figure 1: Number of syllabi that identify A7

Of particular interest, however, is the total number of assignments students in each of these departments will write: ECE has 87 written assignments, ME 105 and CE 33 (Fig. 2). 
Total Number of Written Assignments by Year

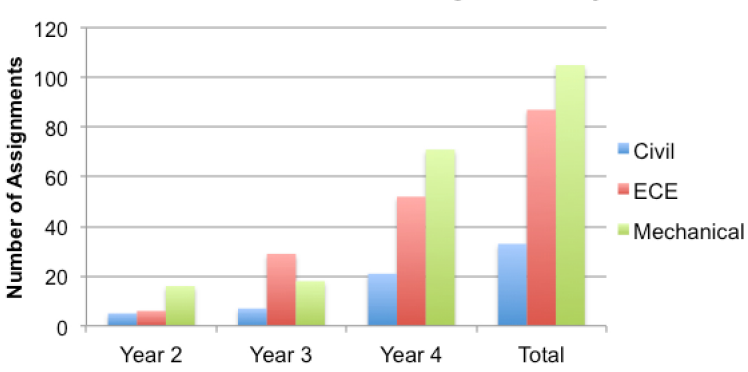

Figure 2: Total number of written assignments by year

While ECE, unlike the other two departments, demands more written assignments in $3^{\text {rd }}$ year, a more noteworthy trend is the increase in the total number of assignments that students must write in each successive year, regardless of the department. On average, ECE students were responsible for 1.9 written assignments per course, ME students for 3.9 written assignments and CE students for 2.4 written assignments. Figure 3 summarizes this trend.

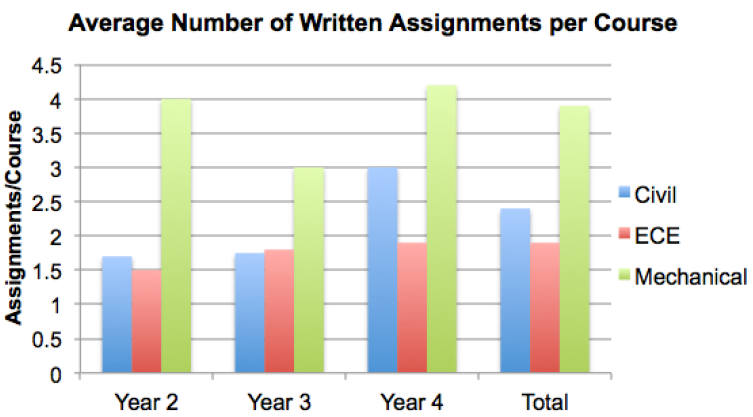

Figure 3: Average number of written assignments per course

Perhaps surprisingly, at least for engineering educators, is the comparison of undergraduate engineering students with those from the disciplines captured by the national study (Fig. 4).

\begin{tabular}{|l|l|l|l|l|l|}
\hline & $\begin{array}{l}\text { Liberal } \\
\text { Arts }\end{array}$ & $\begin{array}{l}\text { Political } \\
\text { Science }\end{array}$ & $\begin{array}{l}\text { Service- } \\
\text { Learning }\end{array}$ & Geography & Nursing \\
\hline Year 1 & $34 / \mathbf{1 . 5}$ & $7 / \mathbf{1 . 4}$ & $42 / \mathbf{1 0}$ & $15 / 3.8$ & $17 / 3.4$ \\
\hline Year 2 & $225 / \mathbf{2 . 5}$ & $39 / \mathbf{2 . 3}$ & $12 / 4$ & $40 / 2.2$ & $33 / 5.5$ \\
\hline Year 3 & $189 / \mathbf{4 . 1}$ & $40 / \mathbf{2 . 4}$ & $35 / \mathbf{6}$ & $24 / \mathbf{1 . 8 5}$ & $50 / 4.2$ \\
\hline Year 4 & $56 / \mathbf{3 . 0}$ & $112 / 4.2$ & $74 / 6.7$ & $107 / 3.5$ & $57 / 4.4$ \\
\hline
\end{tabular}

Figure 4: Average number of assignments by course [National Study]

Here, the first number shown is the total number of assignments in each year of each discipline; the second number is the average number of assignments per course. Of note are the numbers for Political Science and Geography, which are remarkably similar to those for Mechanical Engineering, as shown below in Figure 5.

\begin{tabular}{|l|l|l|l|}
\hline & Civil & Electrical & Mechanical \\
\hline Year 2 & $5 / 1.7$ & $6 / 1.5$ & $16 / 4$ \\
\hline Year 3 & $7 / 1.75$ & $29 / 1.8$ & $18 / 3$ \\
\hline Year 4 & $21 / 3$ & $52 / 1.9$ & $71 / 4.2$ \\
\hline
\end{tabular}

Figure 5: Average assignments per course per year [Faculty of Engineering, University of Manitoba]

Another interesting finding of note is the kinds of assignments listed in the course syllabi, the most common of which are the generic "assignment," the lab report and the "project." The "other" category includes journals, posters and the like - genres that were mentioned at least once but far less frequently than the top three genres (as Fig. 6 shows).

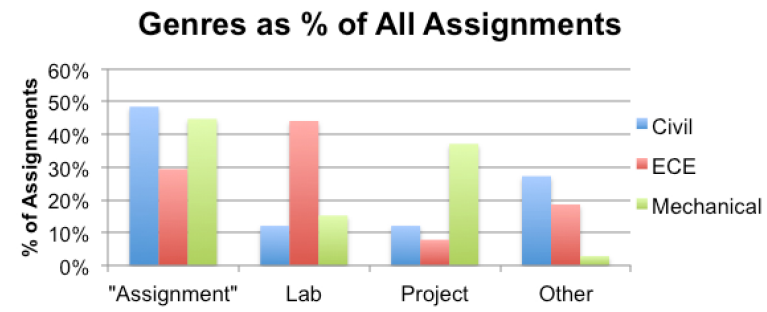

Figure 6: Most common genres

Finally, few course syllabi listed either formative or summative feedback as the feedback provided; rather, most course syllabi claimed to provide both, as shown in Fig. 7.

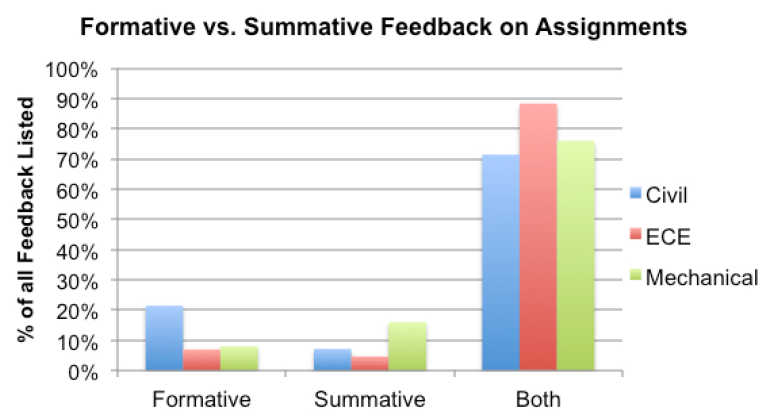

Figure 7: Feedback provided on assignments

These findings, however, are more suggestive than definitive simply because of the paucity of detail given in the course syllabi. Simply put, we have no way of knowing exactly how much writing is actually required for these assignments, nor whether assignments would receive substantial formative feedback. Indeed, the most telling feature of 
the course syllabi we collected was the singular lack of information on the writing that students presumably do in Engineering as we could not determine the length of the assignment; the relative weightings given to the written and the technical components; the audience for the assignment; whether the assignment was "nested" or one part of a larger assignment; or if the students needed to conform to discipline-specific formatting (such as IEEE format).

\section{OBSERVATIONS AND CONCLUSIONS}

In the case of Engineering, where there is a singular lack of guidelines for writing instruction [3], we had hoped that, by collecting and analyzing the course syllabi that each instructor prepares and distributes to students, we could provide the kind of complete "program profiles" that Anson and Dannels promote [2]. However, given the lack of detail in the outlines we collected, that profile is incomplete, though suggestive. Notwithstanding their lack of detail, these course outlines do tell us some interesting things that we can now use as we move forward in our curriculum development.

On the one hand, many of the shortcomings found in these course outlines are not unique; in fact, it is a common problem found throughout the outlines collected for the national study. Indeed, there is great variability across the disciplines [7], [8]. There can even be marked differences between departments within the same discipline, as the frequency of assignments shows in our findings. Nor do we always know what the quality of feedback might be for these various assignments.

Additionally, "engineering faculty, even when they are strong communicators, often lack the requisite content knowledge and familiarity with current research in writing pedagogy and assessment" [10]. Consequently, even though they are experts in the content covered, many engineering professors may be hesitant to include written assignments in their courses; providing meaningful feedback on the writing may likewise just be too daunting a task. Nevertheless, for engineering students to become, not just good writers, but successful writers as well, they need to master the discipline-specific rhetorical demands before they receive the stamp of "communicatively competent" and before they enter the workplace, where students often face many challenges associated with the "contextual nature of all communication" [10].

On the other hand, as common as these shortcomings may be in course outlines from across the disciplines, we can begin the process of helping our engineering students meet these challenges by more firmly connecting the engineering work to the communication of that work, both in our courses and in our outlines [9], [13]; that is, we can promote ways to ensure that students tailor their communications to "best support" the engineering work [11]. For example, this will mean moving away from the template, which tends to treat a genre as a "static recipe" [3], one to be slavishly followed. Rather, we will need to promote the genre as a flexible and "continually adaptive response" to changing exigencies [3] and focus on what the engineering work and the communication demand. As Paretti explains, "writing is not a skill learned once and then repeated forever, like scales on a piano"; rather, "every act of communication is like a new musical piece" - and that means it demands practice and analysis [12]. In this important way, Attribute 7 becomes a practice-based skill - much like the design and problem-solving skills we teach as a matter of course.

One way to do this is to continue to find ways of integrating communication into the engineering courses we teach, such as embedding a communication specialist in courses like the senior design (capstone) courses. This specialist is in a better position to do what writing scholars have long promoted [4], [11]. [14]; namely, that students need to learn the discipline-specific writing genres because doing so helps students to acquire disciplinary knowledge and to shape their work so that the rhetorical demands of the genre are met. At the same time, they gain valuable practice in meeting the needs of the audience.

Another way is to clarify our expectations on our course syllabi. To date, we have at least ensured that our students have a clear picture of what graduate attributes and competency levels we expect of them when they graduate. The next step will be to clarify our expectations in relation to the assignments we demand and the writing we demand.

Finally, communication may then be acknowledged as important to engineering practice [4]. Instead of seeing the technical work as the "real" work [6] and the communication of that work as less critical to engineering success [4], students may at last recognize that communication is integral - even critical - to engineering practice [9].

\section{ACKNOWLEDGEMENTS}

This national study of undergraduate written assignments has been made possible by a grant from the Social Sciences and Humanities Research Council of Canada (SRG RES0006514). We would also like to acknowledge Dr. Roger Graves, Professor, English and Film Studies and Director, Writing Across the Curriculum, University of Alberta. 


\section{REFERENCES}

[1] Accreditation Criteria and Procedures, From the Canadian Engineering Accreditation Board Accreditation Criteria and Procedures, 2008 http://www.engineerscanada.ca/e/files/report ceab 08 .pdf).

[2] Anson, Chris. A. and Deanna Dannels, "Profiling programs: Formative uses of departmental consultations in the assessment of communication across the curriculum," Across the Disciplines: A Journal of Language, Learning and Academic Writing [Online], 6 [Special Issue on Writing Across the Curriculum and Assessment], pp. 1-16, 2009 (Dec.). Available:

http://wac.colostate.edu/atd/assessment/anson_dannels .cfm [May 22, 2012]

[3] Broadhead, Glenn J., "Addressing multiple goals for Engineering writing: The role of course-specific websites," Language and Learning across the Disciplines [Special Issue on Communications across the Engineering Curriculum], v.3, n.2. pp. 19-43, 1999.

[4] Davis, Marjorie T., "Assessing technical communication within Engineering contexts: Tutorial," IEEE Transactions on Professional Communication [Special Section on Assessment in Professional Communication], v.53. n.4, pp. 33-45, 2010.

[5] Ferens, Ken, Jillian Seniuk Cicek, Nariman Sepehri, Witold Kinsner, J.P.Burak, Anne Parker, Dean McNeill, Douglas Ruth, Ian Jeffrey, Norma Godavari, and Sandra Ingram, "Industry Forum III: Towards a common language," in Proc. CEEA Canadian Engineering Education Conference. Sean Maw and Marjan Eggermont (Eds.). (Canmore, AB; 8-11 June), 6 pp., 2014.

[6] Ford, J.D. and L.A. Riley, "Integrating communication and engineering education: A look at curriculum, courses, and support systems," Journal of Engineering Education, October issue, pp.325-328, 2003.

[7] Graves, Roger, "Genre by numbers: A data-driven description of academic discourse," Conference on College Composition and Communication, \{Indianapolis, IN, 22 March), 2014. Available: http://prezi.com/sao9lcamvqg6/genre-by-numbers/
[8] Graves, Roger, Theresa Hyland and Boba Samuels, "Undergraduate writing assignments: An analysis of syllabi at one Canadian college," Written Communication, v.27. n.3. pp. 293-317, 2010.

[9] Orr, Thomas, "Assessment in professional communication: Editorial," IEEE Transactions on Professional Communication [Special Section on Assessment in Professional Communication], v.53, n.4, pp. 1-3, 2010.

[10] Paretti, Marie C. and Lisa D. McNair, "Introduction to the Special Issue on Communication in Engineering Curricula: Mapping the Landscape," IEEE Transactions on Professional Communication, v.51. n.3, pp. 238-241, 2008

[11] Paretti, Marie C., "Teaching communication in capstone design: The role of the instructor in situated learning," Journal of Engineering Education, v.97, no.4, pp. 491-503, 2008.

[12] Paretti, Marie, C. "Communication as professional practice: Designing assignments to develop Engineering professionals," in ASEE Southeast Section Conference, 2005 (The University of Tennessee; Chattanooga TN; 3-5 April), no pp., 2005.

[13] Ramey, D. and J. Hudgins, "The evolution of integrating writing into Engineering: Tracing iterations of writing instruction in a sophomore Engineering course," in Proc. Frontiers in Education Conference, v.3, pp.12b5-1 - 12b5-5, 1999.

[14] Reave, Laura, "Technical Communication instruction in Engineering schools: A survey of topranked U.S. and Canadian programs," Journal of Business and Technical Communication, v.18, no.4, pp. 452-490, 2004. 